\title{
Upward displacement of the odontoid process into the foramen magnum: a palaeopathological case
}

\author{
P. Saccheri, E. Crivellato, F. Toso, L. Travan \\ Department of Medicine, Human Anatomy Section, Udine, Italy \\ [Received: 29 September 2017; Accepted: 30 October 2017]
}

An upward displacement of the odontoid process into the foramen magnum was observed in the skeletal remains of a young male unearthed from a $14^{\text {th }}$ to $17^{\text {th }}$ century cemetery in the north-eastern Italy. Examination of skull bone vestiges and computed tomography scan analysis of the axis exhibited a clear-cut contact zone between the odontoid process and the anterior border of the foramen magnum. In addition, the odontoid process appeared backward deviated. Findings suggest a possible diagnosis of basilar impression/invagination. This anomalous contact may cause compression of neural and vascular structures with a multifaceted series of clinical symptoms. We are unable to set our finding into a complete presumptive diagnostic outline because there is no chance to estimate either the magnitude of the whole craniovertebral junction defect but we believe that the present case contributes to the general knowledge of the craniovertebral region and to bone pathology in ancient times. (Folia Morphol 2018; 77, 3: 604-608)

Key words: basilar invagination, basilar impression, odontoid retroflexion, craniovertebral junction, dens height, porotic lesions, paleopathology

\section{INTRODUCTION}

The foramen magnum (FM) connects the posterior cranial fossa to the vertebral canal. Broadly speaking, this aperture encompasses the caudal part of the brainstem, the cerebellum, the fourth ventricle, the rostral part of the spinal cord, and the lower cranial and upper cervical nerves. Geometrical profile of this critical zone may be modified by congenital or acquired conditions. In turn, reduction of foramen size may result in compression of neurological and vascular structures with emergence of complex clinical symptoms, syringomyelia, obstructive hydrocephalus or even death. Upward displacement of the odontoid process into the foramen magnum is one of such conditions.
When the cause of the displacement is a developmental failure the condition is termed "basilar invagination" [9]; it is often associated with malformations of the axial skeleton (platybasia, hypoplasia of the clivus and/or the occipital condyles, atlanto-occipital assimilation, atlas hypoplasia, Klippel-Feil syndrome) and neural abnormalities (Chiari malformations, syringomyelia, hydrocephalus) [14]. When the prolapse results from acquired diseases causing the softening of the skull base (such as rickets, Paget disease, hyperparathyroidism, osteogenesis imperfecta) it is called "basilar impression" [15]. Lastly, the migration of the dens in rheumatoid arthritis is termed "cranial settling" [10]. 


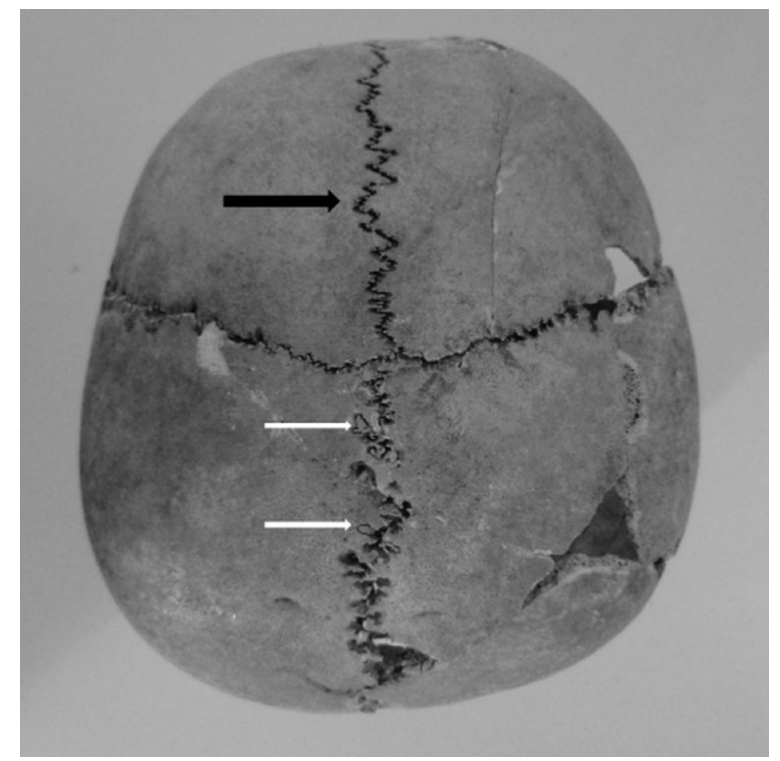

Figure 1. Calvarium. The metopic suture is still present (black arrow). Small wormian bones are visible along the sagittal suture (white arrows).

Currently, diagnosis of basilar impression and invagination is based on a variety of craniometric measurements.

Here, we report such a finding in a human skeleton unearthed from an ancient Italian cemetery.

\section{MATERIALS AND METHODS}

In 2006, human skeletons were unearthed from a $14^{\text {th }}$ to $17^{\text {th }}$ century cemetery located in Chiopris (northeast Italy). One of them, object of the present work, was named T2C.

Osteological study was performed according to standard methods [2]. Computerised tomography and digital tomosynthesis were executed.

Axis height was assessed between the base of the body and the tip of the dens. According to Tubbs et al. [17], dens height was the distance from the dentocentral synchondrosis to the apex of the process. Two angles $(a, b)$ were measured [17]. Angle a was determined between the line joining the tip of dens and the midpoint of the dentocentral synchondrosis. Angle $b$ was calculated between the line tangent to the base of $\mathrm{C} 2$ and the line through the apex of the dens.

\section{RESULTS}

According to pelvis and skull morphology, maturation of long-bones epiphyses, the state of dentition and persistence of spheno-occipital synchon- drosis, skeletal remains were estimated to belong to a 16-18-year-old male. In the skull, the metopic suture was identifiable (Fig. 1). Several bones in the cranial base and splanchnocranium were injured or absent, thus preventing the complete reconstruction of the skull. The occipital bone, fragmented, displayed an anomalous contact between the dens and the anterior border of the FM (Fig. 2). Axis height and the height of the dens were $38.2 \mathrm{~mm}$ and $24.6 \mathrm{~mm}$, respectively. In the sagittal plane, the dens revealed a remarkable posterior tilt. Angle a measured $61.6^{\circ}$; angle b, $60.15^{\circ}$ (Fig. 3).

Although in a fragmented state, atlas bone appeared normally shaped with no unusual features. The rest of the spine was normal. Porotic lesions in moderate/mild degree were detected (cribra orbitalia and femoral cribra) (Fig. 4). The cause of death could not be determined.

\section{DISCUSSION}

The osteological study of $\mathrm{T} 2 \mathrm{C}$ reveals two major findings. The first is the upward bulging of the dens into the foramen magnum; the second is the backward inclination of the dens. These features coexist with a condition of multiple porotic lesions in the roof of the orbit and the anatomical neck of femora.

Any protrusion of the dens beyond the FM is abnormal. The mean value of the basion-dens interval, i.e. the distance between the tip of the dens and the lowest point on the anterior rim of the $\mathrm{FM}$, has been found to be $4.59 \mathrm{~mm}$ and $6.2 \mathrm{~mm}$ in an adult population and in children with ossification of the ossiculum terminale, respectively $[1,13]$.

As to the tilt of the dens, an association between basilar invagination/impression, retroflexed/retroverted dens and Chiari I malformation was reported $[11,16,18]$.

Tubbs et al. [17] analysed the correlation between the degree of posterior tilt and Chiari I malformation in children aged 17 months-18 years. In the control cohort, the mean value of angle a was $97 \pm 5.1^{\circ}$; the mean value of angle $b$ was $95 \pm 6.6^{\circ}$. In patients with Chiari I malformation the mean values of angles $a$ and $b$ were found to be $84.6^{\circ}$ and $67.04^{\circ}$, respectively. Furthermore, higher grades of odontoid retroflexion were positively correlated with syringomyelia.

In 125 healthy adult subjects, angle a was found to range from $70^{\circ}$ to $89^{\circ}$ (mean $79.3^{\circ}$ ) and angle $b$ from $57^{\circ}$ to $87^{\circ}$ (mean $71.9^{\circ}$ ) [5]. Therefore, in normal adults, odontoid process tends to be longer and 


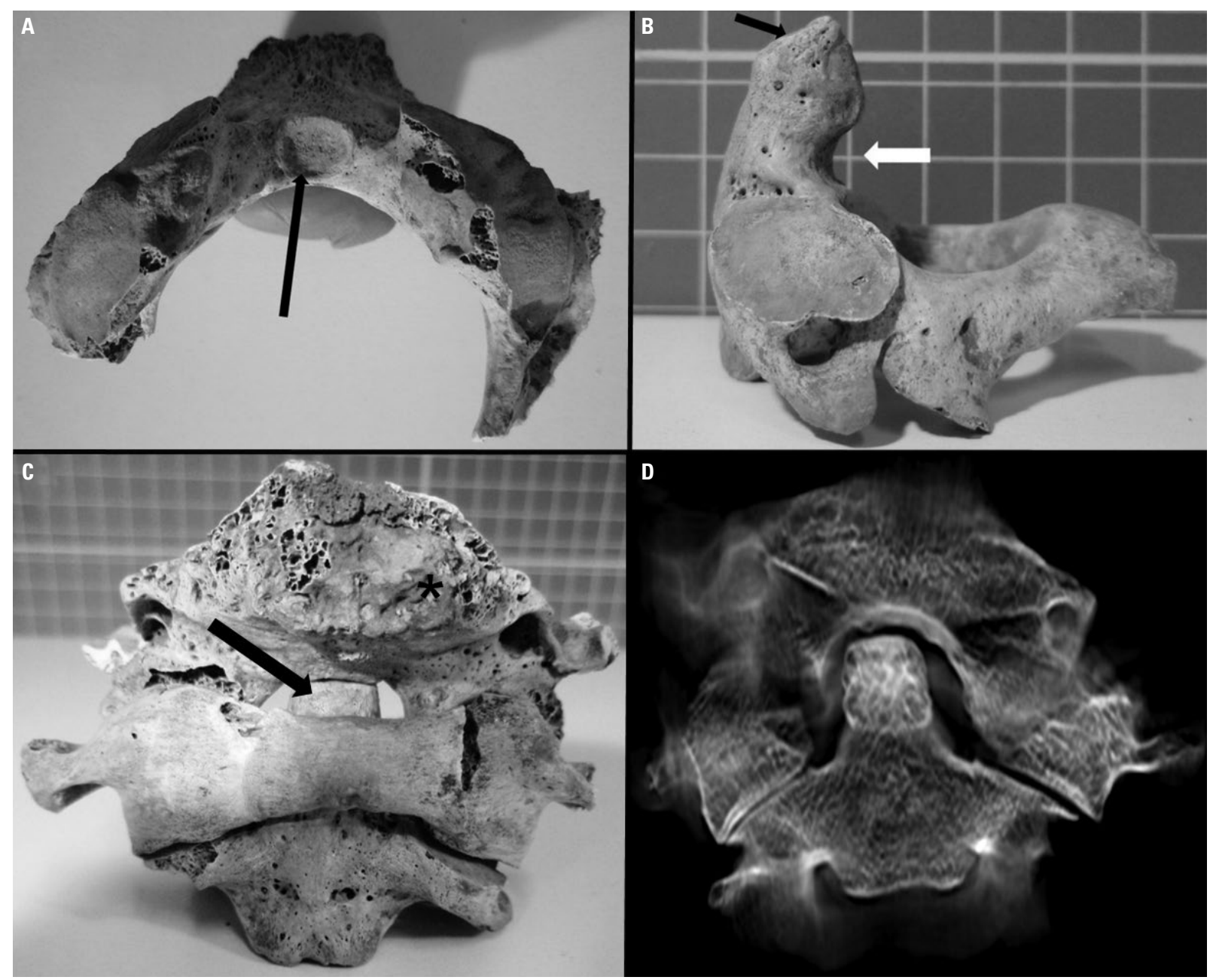

Figure 2. A. Basilar apophysis and lateral masses of the occipital bone, ectocranial surface. The black arrow indicates the impression left by the dens on the anterior margin of the foramen magnum; B. Axis, parasagittal view. The deep sulcus caused by the transverse ligament (white arrow) as well the impression due to the contact with the occipital bone (black arrows) are well appreciable; $\mathbf{C}$. The craniovertebral complex, coronal plane, anterior view. The relationship between the dens and the foramen magnum is well appreciable (black arrow). The asterisk indicates the occipital surface of spheno-occipital synchondrosis, still open; D. Coronal tomographic reconstruction based on digital tomosynthetic acquisition. Image well shows the abnormal notch of the anterior profile of the foramen magnum with cortical osteosclerosis due to the abnormal pseudo-joint with the odontoid process.
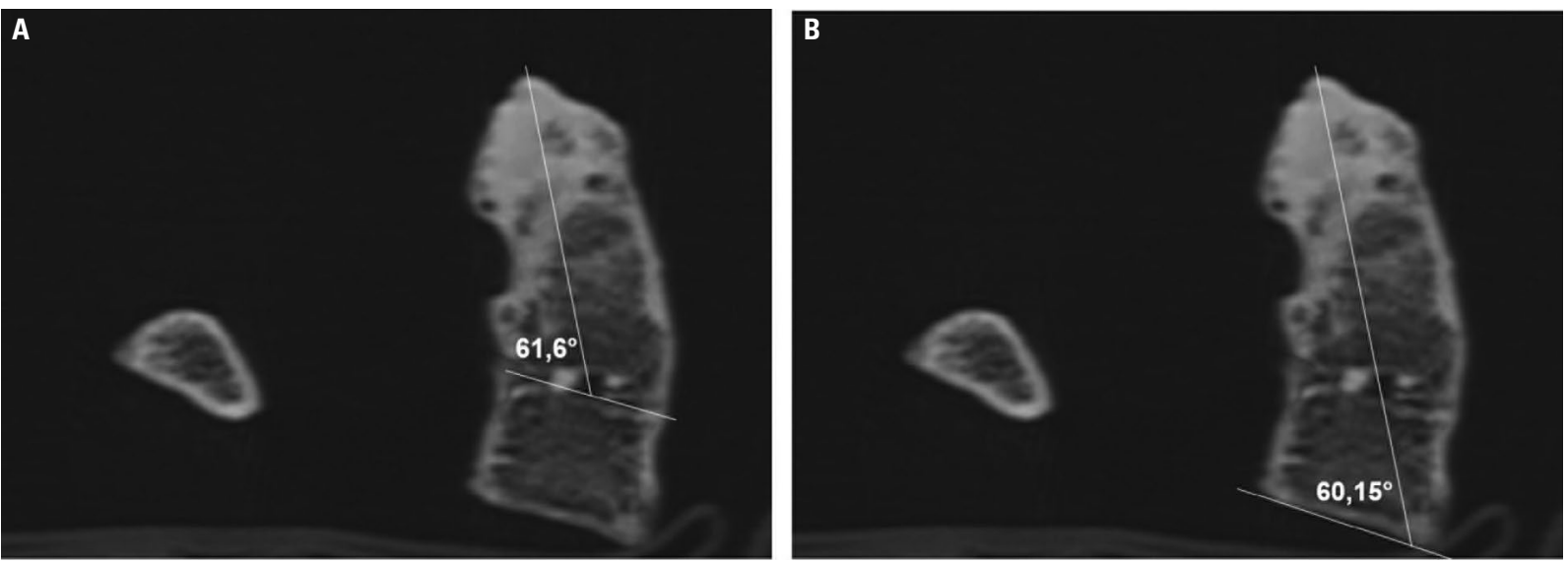

Figure 3. Axis, computed tomography scan, parasagittal view. A. Angle a, related to dens retroflexion; B. Angle b, expressing dens retroversion. 

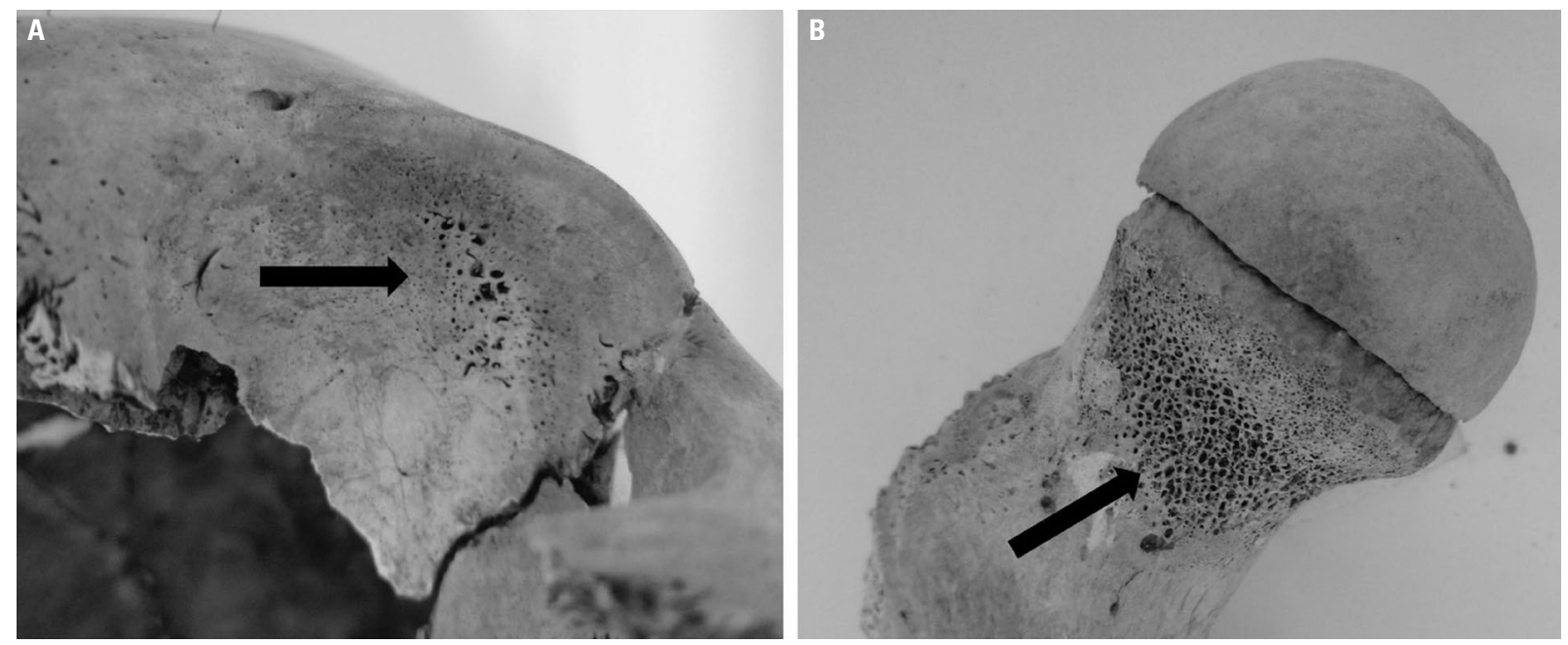

Figure 4. A. Orbital roof with cribra orbitalia (black arrow). B. Porotic bone area (femoral cribra) on the anterior surface of collum femoris (black arrow). The femoral head has not begun to unite.

Table 1. Cases of basilar impression/invagination documented in palaeopathological records

\begin{tabular}{|c|c|c|c|c|c|c|}
\hline $\begin{array}{l}\text { First author, year } \\
\text { [reference] }\end{array}$ & Sex & Age & Material & $\begin{array}{c}\text { Basilar } \\
\text { impression }\end{array}$ & $\begin{array}{c}\text { Basilar } \\
\text { invagination }\end{array}$ & Symptoms/associated anomalies \\
\hline Campillo, 2005 [3] & Female & Not available & Skeletal remains & $\mathrm{x}$ & & Platybasia, possible Arnold-Chiari malformation \\
\hline Campillo, 2005 [3] & Male & Adult & Skeletal remains & $x$ & & Platybasia, atlas assimilation, C2-C3 fusion \\
\hline Pany, 2007 [12] & Male & Juvenile & Skeletal remains & $x$ & & $\begin{array}{l}\text { Klippel-Feil syndrome with hypoplasia of the } \\
\text { pars basilaris of the occipital bone, C2-C3 and } \\
\text { Th2-Th3 fusion, spina bifida occulta. Extensive } \\
\text { porosities of the cortical bone }\end{array}$ \\
\hline Lowenstein, 2009 [6] & Not available & Infant & Mummy & $x$ & & Platybasia, osteogenesis imperfecta \\
\hline Mann et al., 2013 [7] & Male & Adult & Skeletal remains & & $x$ & Platybasia, craniosynostosis, aplasia of the dens \\
\hline $\begin{array}{l}\text { Marchewka et al., } \\
2017[8]\end{array}$ & Not available & Infant & Skeletal remains & $x$ & & $\begin{array}{l}\text { Klippel-Feil syndrome with C3-C4 fusion, } \\
\text { possible spina bifida occulta }\end{array}$ \\
\hline
\end{tabular}

more backward tilted. In the present case, despite the subadult age, the dimensions of the axis appeared comparable with that of adult population. However, also in this case, the angle a $61.6^{\circ}$ shows a high grade of retroflexion.

Our investigation has intrinsic limits. A distinction between basilar impression and invagination results impossible. Although cranial malformations may occasionally be implicated in the persistence of a metopic suture, commonly metopism is an anatomical variant (incidence about $10 \%$ in Italy) both in the past and present epoch [4].

The remaining cervical vertebrae appeared normal but the lack of many part of the skull did not permit to evaluate other anomalies and, of course, we did not know anything about neural structures involvement. The porotic lesions, very frequent in ancient populations, represent an additional confounding feature. Characteristic of immature skeletons, porotic lesions have been attracting scientific attention since 1885 [20]. Even if there is no agreement between the researchers about their aetiology, these lesions are considered morphological features of anaemia and nutritional deficiencies, such as vitamins C, D and B12 deficiency. These different aetiologies are not mutually exclusive and in the same individual insufficient dietary intake and inadequate absorption of vitamins, due to chronic diarrheal diseases or parasites, could coexist [19]. Therefore, in the present case, a softening of the bone tissue of the base of the skull, due for example to a deficiency of vitamin $D$, could not be ruled out.

Only a few cases of basilar impression/invagination from ancient times have been documented in palaeopathological literature (Table 1). 


\section{CONCLUSIONS}

Observations carried out on ancient skeletons are rarely unequivocal and the present case does not represent an exception. Nevertheless, palaeopathological records can provide valuable information on normal and abnormal anatomy of the skeletal system and are undoubtedly powerful tools for taking a glimpse in the life of our ancestors.

\section{REFERENCES}

1. Bertozzi JC, Rojas CA, Martinez CR. Evaluation of the pediatric craniocervical junction on MDCT. AJR Am J Roentgenol. 2009; 192(1): 26-31, doi: 10.2214/ajr.192.5_ supplement.0a26, indexed in Pubmed: 19098175.

2. Buikstra JE, Ubelaker DH. Standards for data collection from human skeletal remains. Fayetteville: Arkansas Archaeological Survey Research Series No. 44. 1994.

3. Campillo D. Paleoradiology. II: congenital and hereditary malformations of the skeleton. J Paleopath. 2005; 17: 45-64.

4. Hanihara $T$, Ishida $H$. Frequency variations of discrete cranial traits in major human populations. II. Hypostotic variations. J Anat. 2001; 198(Pt 6): 707-725, indexed in Pubmed: 11465863.

5. Khaleel ZL, Besachio DA, Bisson EF, et al. Estimation of odontoid process posterior inclination, odontoid height, and pB-C2 line in the adult population. J Neurosurg Spine. 2014; 20(2): 172-177, doi: 10.3171/2013.10.SPINE13405, indexed in Pubmed: 24313675.

6. Lowenstein EJ. Osteogenesis imperfecta in a 3,000-yearold mummy. Childs Nerv Syst. 2009; 25(5): 515-516, doi: 10.1007/s00381-009-0817-7, indexed in Pubmed: 19212769.

7. Mann RW, Tuamsuk P, Hefner JT. Aplasia of the os odontoideum: Skeletal manifestation from Thailand. Int J Paleopathol. 2013; 3(4): 302-306, doi: 10.1016/j. ijpp.2013.08.001, indexed in Pubmed: 29539568.

8. Marchewka J, Borowska-Strugińska B, Czuszkiewicz J, et al. Cervical Spine Anomalies: Children in One of the Oldest Churches in Poland. Int J Osteoarchaeol. 2017; 27(5): 926-934, doi: 10.1002/oa.2608.

9. Menezes A. Craniocervical developmental anatomy and its implications. Child's Nervous System. 2008; 24(10): 1109-1122, doi: 10.1007/s00381-008-0600-1.
10. Menezes AH, VanGilder JC, Clark CR, et al. Odontoid upward migration in rheumatoid arthritis. An analysis of 45 patients with "cranial settling". J Neurosurg. 1985; 63(4): 500-509, doi: 10.3171/jns.1985.63.4.0500, indexed in Pubmed: 4032013.

11. Milhorat TH, Chou MW, Trinidad EM, et al. Chiari I malformation redefined: clinical and radiographic findings for 364 symptomatic patients. Neurosurgery. 1999; 44(5): 1005-1017, indexed in Pubmed: 10232534.

12. Pany D, Teschler-Nicola M. Klippel-Feil syndrome in an Early Hungarian Period juvenile skeleton from Austria. Int J Osteoarchaeol. 2007; 17(4): 403-415, doi: 10.1002/ oa.880.

13. Radcliff KE, Ben-Galim P, Dreiangel N, et al. Comprehensive computed tomography assessment of the upper cervical anatomy: what is normal? Spine J. 2010; 10(3): 219-229, doi: 10.1016/j.spinee.2009.12.021, indexed in Pubmed: 20207332.

14. Smith J, Shaffrey C, Abel M, et al. Basilar Invagination. Neurosurgery. 1994; 66(suppl_3): A39-A47, doi: 10.1227/01. neu.0000365770.10690.6f.

15. Smoker WR. Craniovertebral junction: normal anatomy, craniometry, and congenital anomalies. Radiographics. 1994; 14(2): 255-277, doi: 10.1148/radiographics.14.2.8190952, indexed in Pubmed: 8190952.

16. Tubbs RS, Beckman J, Naftel RP, et al. Institutional experience with 500 cases of surgically treated pediatric Chiari malformation Type I. J Neurosurg Pediatr. 2011; 7(3): 248-256, doi: 10.3171/2010.12.PEDS10379, indexed in Pubmed: 21361762.

17. Tubbs RS, Wellons JC, Blount JP, et al. Inclination of the odontoid process in the pediatric Chiari I malformation. J Neurosurg. 2003; 98(1 Suppl): 43-49, indexed in Pubmed: 12546387.

18. Von To, Gehle W. The upper cervical spine: regional anatomy, pathology, and traumatology. A systematic radiological atlas and textbook. Grune \& Stratton, New York 1972.

19. Walker PL, Bathurst RR, Richman R, et al. The causes of porotic hyperostosis and cribra orbitalia: a reappraisal of the iron-deficiency-anemia hypothesis. Am J Phys Anthropol. 2009; 139(2): 109-125, doi: 10.1002/ajpa.21031, indexed in Pubmed: 19280675.

20. Welcker H. Die Abstammung der Bevölkerung von Socotra. Deutscher Geographentag, Hamburg 1885. 